\title{
ONDERZOEKINGEN OVER DE VEEREN BIJ HOENDERACHTIGE VOGELS.
}

\author{
DOOR \\ Dr. J. H. KRUIMEL, \\ Biologisch assistent van het Koninklijk Zoologisch Genootschap "Natura Artis Magistra”.
}

Met 4 platen en 4 tekstfiguren. 
Aan

Het Koninklijk Zoologisch Genootschap NATURA ARTIS MAGISTRA. 